\title{
Article \\ A Comparison of Microfluidic-Jet Spray Drying, Two-Fluid Nozzle Spray Drying, and Freeze-Drying for Co-Encapsulating $\beta$-Carotene, Lutein, Zeaxanthin, and Fish Oil
}

\author{
Yongchao Zhu ${ }^{1}$, Yaoyao Peng ${ }^{1}$, Jingyuan Wen ${ }^{2}$ and Siew Young Quek ${ }^{1,3, *(D)}$ \\ 1 Food Science, School of Chemical Sciences, The University of Auckland, Auckland 1010, New Zealand; \\ yzhu313@aucklanduni.ac.nz (Y.Z.); ypen083@aucklanduni.ac.nz (Y.P.) \\ 2 School of Pharmacy, Faculty of Medical and Health Sciences, The University of Auckland, \\ Auckland 1023, New Zealand; j.wen@auckland.ac.nz \\ 3 Riddet Institute, Massey University, Palmerston North 4442, New Zealand \\ * Correspondence: sy.quek@auckland.ac.nz
}

check for updates

Citation: Zhu, Y.; Peng, Y.; Wen, J.; Quek, S.Y. A Comparison of Microfluidic-Jet Spray Drying, Two-Fluid Nozzle Spray Drying, and Freeze-Drying for Co-Encapsulating $\beta$-Carotene, Lutein, Zeaxanthin, and Fish Oil. Foods 2021, 10, 1522 https://doi.org/10.3390/ foods10071522

Academic Editor: Jayani Chandrapala

Received: 26 April 2021

Accepted: 17 June 2021

Published: 1 July 2021

Publisher's Note: MDPI stays neutral with regard to jurisdictional claims in published maps and institutional affiliations.

Copyright: (C) 2021 by the authors. Licensee MDPI, Basel, Switzerland. This article is an open access article distributed under the terms and conditions of the Creative Commons Attribution (CC BY) license (https:// creativecommons.org/licenses/by/ $4.0 /)$

\begin{abstract}
Various microencapsulation techniques can result in significant differences in the properties of dried microcapsules. Microencapsulation is an effective approach to improve fish oil properties, including oxidisability and unpleasant flavour. In this study, $\beta$-carotene, lutein, zeaxanthin, and fish oil were co-encapsulated by microfluidic-jet spray drying (MFJSD), two-fluid nozzle spray drying (SD), and freeze-drying (FD), respectively. The aim of the current study is to understand the effect of different drying techniques on microcapsule properties. Whey protein isolate (WPI) and octenylsuccinic anhydride (OSA) modified starch were used as wall matrices in this study for encapsulating carotenoids and fish oil due to their strong emulsifying properties. Results showed the MFJSD microcapsules presented uniform particle size and regular morphological characteristics, while the SD and FD microcapsules presented a large distribution of particle size and irregular morphological characteristics. Compared to the SD and FD microcapsules, the MFJSD microcapsules possessed higher microencapsulation efficiency (94.0-95.1\%), higher tapped density $\left(0.373-0.652 \mathrm{~g} / \mathrm{cm}^{3}\right)$, and higher flowability (the Carr index of 16.0-30.0\%). After a 4-week storage, the SD microcapsules showed the lower retention of carotenoids, as well as $\omega$-3 LC-PUFAs than the FD and MFJSD microcapsules. After in vitro digestion trial, the differences in the digestion behaviours of the microcapsules mainly resulted from the different wall materials, but independent of drying methods. This study has provided an alternative way of delivering visual-beneficial compounds via a novel drying method, which is fundamentally essential in both areas of microencapsulation application and functional food development.
\end{abstract}

Keywords: microfluidic-jet spray drying; co-encapsulation; $\beta$-carotene; lutein; zeaxanthin; fish oil; in vitro digestion

\section{Introduction}

Visual impairment and blindness greatly reduce the quality of life, and pose huge socioeconomic burdens to families due to the high costs of public health treatments [1]. According to the World Health Organisation (WHO)'s World Report on Vision 2019 [2], at least 2.2 billion people globally have vision impairments or blindness; however, from this number, at least 1 billion people have vision impairments that could have been prevented or have not been addressed. Therefore, seeking alternative ways to prevent or assist with treating visual problems has long been a popular topic.

Some lipophilic bioactives were reported to be effective at preventing common ocular diseases, including cataracts and age-related macular degeneration (AMD). Among them, $\beta$-carotene has gained much attention for its high provitamin A activity, which can prevent the ocular diseases related to vitamin A deficiency [3,4]. In addition, lutein and zeaxanthin 
are capable of preventing macular degeneration and cataracts, and have a filtering effect on harmful blue light to prevent photooxidation [5,6]. Fish oil, on the other hand, is a rich source of $\omega-3$ long chain polyunsaturated fatty acids ( $\omega-3$ LC-PUFAs), including eicosapentaenoic acid (EPA, C20:5n-3) and docosahexaenoic acid (DHA, C22:6n-3) [7]. Studies reported that fish oil is effective in the treatment of dry eye disease and AMD [8-10]. Nevertheless, the inherent chemical reactivities of these lipophilic compounds make them sensitive to oxygen, light, and heat, which greatly limit their applications in functional foods or pharmaceuticals [11]. Thus, an effective way of delivering these functional compounds is of great interest to global researchers.

Microencapsulation is a feasible approach to preserve the chemical integrity and physiological benefits of bioactive compounds. There are many microencapsulation techniques available and each technique has its own characteristics. The two-fluid nozzle spray drying (SD) and freeze-drying (FD) have been widely applied in the microencapsulation of lipophilic bioactives. The two-fluid nozzle spray dryer produces polydisperse droplets and dehydrates the fine droplets by hot air, while freeze-drying, also known as lyophilisation, is a drying technique to remove water from heat-sensitive materials at low temperature [12,13].

The microfluidic-jet spray drying (MFJSD) is a relatively novel spray-drying technique that produces monodisperse microparticles with narrow size distribution and uniform morphology [14]. MFJSD is equipped with a monodisperse droplet generator, which is capable of atomizing the feed solution into monodispersed droplets with a vertical droplet trajectory [15]. Each individual droplet could be ensured of an identical drying history and, thus, the variable of droplet size can be effectively minimised [16]. The application of MFJSD can reduce the complexity of spray-dried droplets and decrease the possibility of powder agglomeration to improve the flowability of dried particles. At present, the studies on bioactive encapsulation by MFJSD are still quite limited, and none of them has reported on the co-encapsulation of carotenoids and fish oil.

This study aims to understand the drying technique effects on the properties, storage stability, and digestibility of the microcapsules containing three carotenoids ( $\beta$-carotene, lutein, zeaxanthin), and fish oil. This is also the first study on a systematic comparison among the MFJSD, SD, and FD, regarding their feasibility and efficiency in co-encapsulating carotenoids and fish oil.

\section{Materials and Methods}

\subsection{Samples and Chemicals}

Fish oil (Incromega TG3322) was kindly donated by Croda International (Snaith, England, UK). Carotenoids, including $\beta$-carotene, lutein, and zeaxanthin were provided as gifts by DSM Nutritional Products (Heerlen, Netherlands). Whey protein isolate (WPI) was supplied by Fonterra Co-operative Group Limited (Auckland, New Zealand). Octenylsuccinic anhydride (OSA) modified starch (HI-CAP100) was purchased from Ingredion (Westchester, IL, USA). Methyl heptadecanoate, butylated hydroxytoluene (BHT) was obtained from Sigma-Aldrich (St. Louis, MO, USA). Reagents of electrolyte stock solutions for in vitro digestion were as follows: sodium carbonate, calcium chloride dehydrate, sodium chloride, sodium hydrogen carbonate, potassium phosphate and potassium chloride from ECP Ltd. (Auckland, New Zealand); magnesium chloride hexahydrate from Scharlau (Barcelona, Spain); ammonium carbonate from Ajax FineChem (Wollongong, Australia); $\alpha$-amylase and pepsin (from porcine gastric mucosa), pancreatin (from porcine pancreas), and bile salts from Sigma-Aldrich (St. Louis, MO, USA). Nile Blue for oil stain was obtained from Sigma-Aldrich (St. Louis, MO, USA). All chemicals used in this study were of analytical grade.

\subsection{Preparation of Emulsion}

WPI and OSA modified starch was dissolved in water with constant stirring at $55^{\circ} \mathrm{C}$ and $80^{\circ} \mathrm{C}$, respectively, for $60 \mathrm{~min}$, using a magnetic hot plant (IKA RCT basic, German), 
followed by stirring overnight at room temperature for complete dispersion. An oil phase containing fish oil $(99.55 \%), \beta$-carotene $(0.15 \%)$, lutein $(0.15 \%)$, and zeaxanthin $(0.15 \%)$ was firstly prepared before it was mixed with the above aqueous phase to prepare an emulsion with $20 \%(w / w)$ total solid content $(16 \% w / w$ wall materials and $4 \% w / w$ oil phase). Three wall materials were studied: WPI only, OSA only, and a combination of WPI/OSA $(50 / 50 w / w)$. The resulting mixtures were then homogenised using a highspeed mixer (L5T, Silverson, East Longmeadow, MA, USA) at $2000 \mathrm{rpm}$ for $5 \mathrm{~min}$ to make pre-emulsions. This was followed by homogenization with a pneumatic microfluidizer (HC-2000, Microfluidics Inc., Newton, MA, USA) at 12,000 psi for 3 passes (parameters were selected from initial trials) to obtain three fine emulsions, namely WPI emulsion, OSA emulsion and WO emulsion.

\subsection{Co-Encapsulation of Carotenoids and Fish Oil \\ 2.3.1. Two-Fluid Nozzle Spray Drying}

Microencapsulation by SD was conducted using the Buchi Mini Spray Dryer B-191 (Buchi Corporation, Flawil, Switzerland). The schematic diagram of a typical two-fluid nozzle spray dryer was shown in Figure 1A. The inlet temperature was set at $180{ }^{\circ} \mathrm{C}$, the aspirator was at $90 \%$ and the pump rate was at $20 \%$. Three microcapsules-SD-W, SD-O, and SD-WO — encapsulated by WPI only, OSA only, and a combination of WPI/OSA $(50 / 50 w / w)$, respectively, were obtained. The obtained powder was transferred to a $50 \mathrm{~mL}$ centrifuge tube, flushed with nitrogen, and stored in a vacuum desiccator at room temperature until required.

\subsubsection{Freeze-Drying}

The emulsions were placed in $50 \mathrm{~mL}$ centrifuge tubes and were kept at $-80{ }^{\circ} \mathrm{C}$ for $24 \mathrm{~h}$ before being transferred to the freeze dryer (FreezeZone 12 Plus, Labconco, Kansas, $\mathrm{MO}, \mathrm{USA})$. During the drying process, the temperature and the vacuum pressure was set at $-81{ }^{\circ} \mathrm{C}$ and at 0.014 torr, respectively. The dried samples were collected after $72 \mathrm{~h}$ of drying, and were further ground into fine powders. Three microcapsules, FD-W, FD-O, and FD-WO using WPI only, OSA only, and a combination of WPI/OSA (50/50 w/w), respectively, as wall materials, were obtained, and stored following the same procedure as described in Section 2.3.1

\subsubsection{Microfluidic-Jet Spray Drying}

The schematic diagram of a typical microfluidic-jet spray dryer is shown in Figure 1B. Feed emulsions were firstly added into the thermostatic heating reservoir of the spray dryer and were kept at $50{ }^{\circ} \mathrm{C}$ during the spray drying process. A $75 \mu \mathrm{m}$-diameter nozzle atomizer was used for MFJSD in this study. The spray drying conditions was modified according to previous studies $[17,18]$. The flow pressure was $0.4 \mathrm{psi}$, inlet temperature was $180^{\circ} \mathrm{C}$, and outlet temperature was controlled in a range of $85-90^{\circ} \mathrm{C}$. The dried powders were collected into $50 \mathrm{~mL}$ centrifuge tubes, which were then flushed with nitrogen and stored in desiccator containers at $25^{\circ} \mathrm{C}$ until further analyses. Again, three microcapsule samples, MFJSD-W, MFJSD-O, and MFJSD-WO, were produced using WPI only, OSA only, and mixed WPI/OSA (50/50 w/w), respectively, as wall materials, and they were stored as detailed in Section 2.3.1.

\subsection{Physiochemical Properties of Microcapsules}

2.4.1. Water Activity

Water activity $\left(\mathrm{a}_{\mathrm{W}}\right)$ was determined by a water activity analyser (TH-500, Novasina, Switzerland) with sensor temperature set at $25{ }^{\circ} \mathrm{C}$. An appropriate amount of powder sample was placed in the sample pan, and the $\mathrm{a}_{\mathrm{w}}$ of each sample was obtained when equilibrium was reached. 


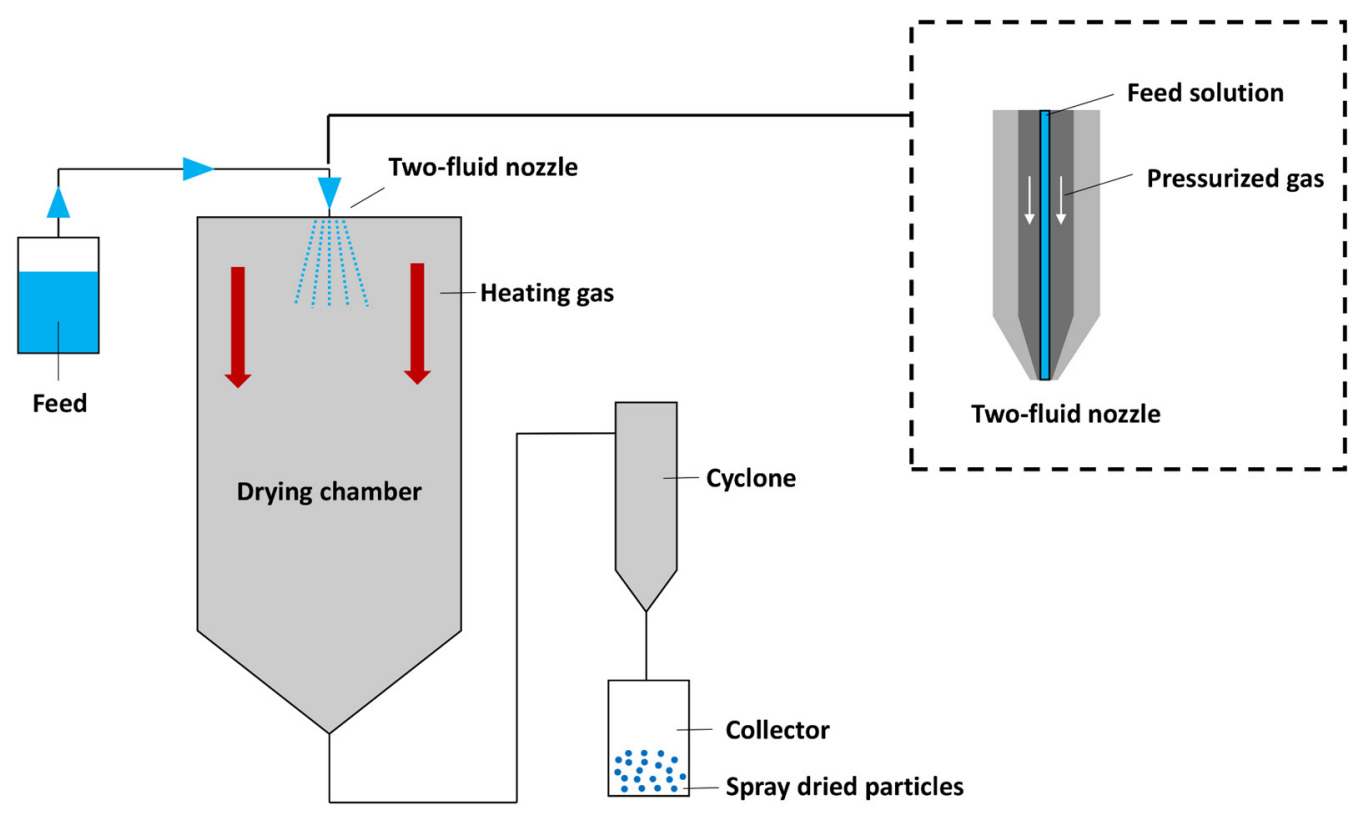

(A)

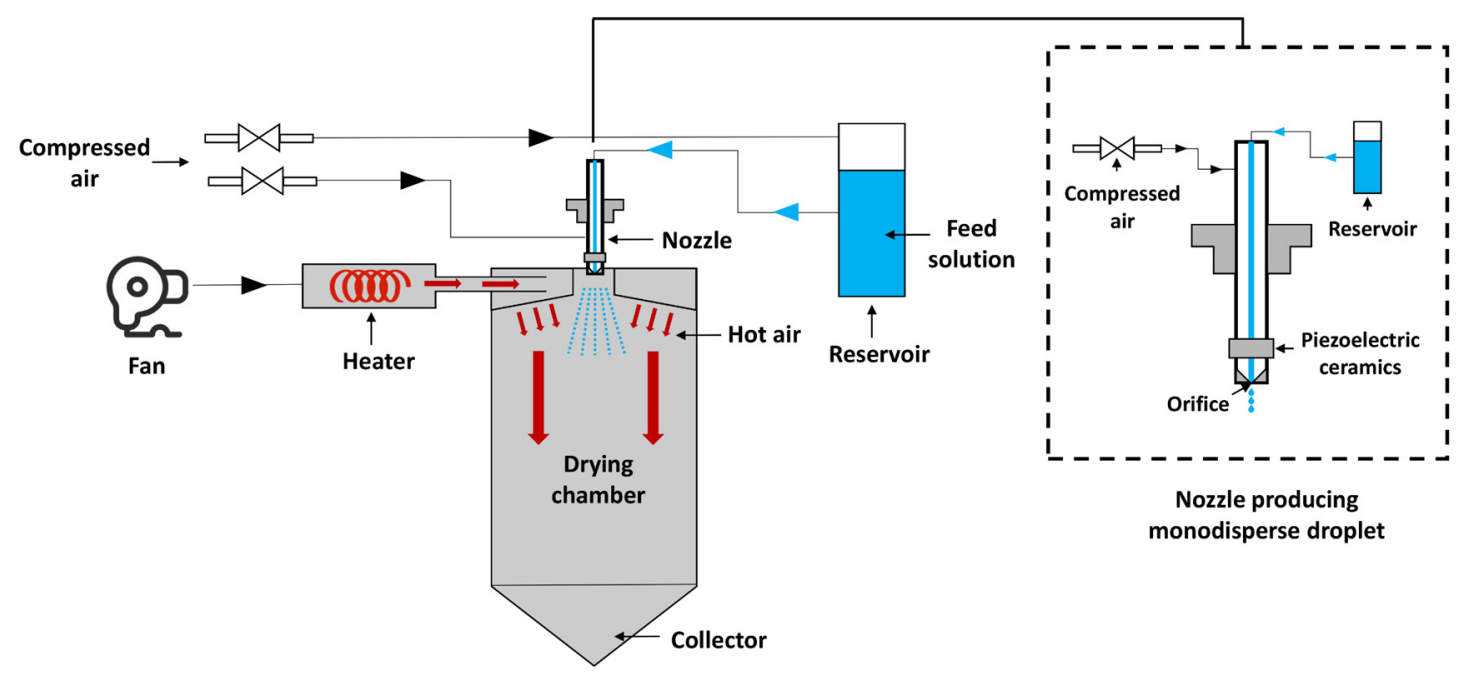

(B)

Figure 1. Schematic diagram of (A) two-fluid nozzle spray dryer, (B) microfluidic-jet spray dryer.

\subsubsection{Density and Flowability}

The density of microcapsules was measured according to Rizi et al. [19]. One gram of the microcapsules was transferred to a $10 \mathrm{~mL}$-measuring cylinder. The initial volume was recorded to calculate the bulk density as $\mathrm{g} / \mathrm{cm}^{3}$. The same cylinder was then tapped until 
the volume of the microcapsules remained unchanged, and the tapped density $\left(\mathrm{g} / \mathrm{cm}^{3}\right)$ was calculated using the second volume. The Carr index was determined by formula (1).

$$
\text { Carr index }=[(\text { Bulk density }- \text { Tapped density }) / \text { Bulk density }] \times 100 \%
$$

\subsubsection{Microencapsulation Efficiency}

Microencapsulation efficiency (ME) of the dried powders was evaluated according to the method by Carneiro et al. [20]. A total of $0.5 \mathrm{~g}$ of powder was transferred into a $50 \mathrm{~mL}$ centrifuge tube, followed by the addition of $5 \mathrm{~mL}$ of hexane. The mixture was gently vortexed for $2 \mathrm{~min}$ to extract the surface oil and then filtered with a filter paper (Filter Paper MS2 $70 \mathrm{~mm}$, MicroAnalytix). The filtered powder was rinsed three times, each with $5 \mathrm{~mL}$ of hexane. The hexane was combined and was further removed from the extracted oil by nitrogen-blow. The encapsulation efficiency was calculated by formula (2).

Microencapsulation efficiency $(\%)=[($ Total oil $(\mathrm{g})-$ Surface oil $(\mathrm{g})) /$ Total oil $(\mathrm{g})] \times 100 \%$

\subsubsection{Droplet Size and Particle Size Distribution}

The microcapsules were re-dispersed into water, and the droplet size and particle size distribution (PDI) of the resultant dispersions were measured using a Zetasizer Nano ZS (Malvern, Herrenberg, Germany). Each sample was diluted to $0.1 \%(w / w)$ to prevent multiple scattering effects. One millilitre of each diluted sample was added to the cuvette and measured at $25^{\circ} \mathrm{C}$.

\subsection{Morphological Observation on Microcapsules}

The microstructure of the microcapsules was examined using a table top scanning electron microscope (SEM) (Hitachi TM3030Plus, Tokyo, Japan). The samples were placed on the SEM stubs using two-sided adhesive tape and then coated with gold by a desk sputter coater (DSR1, Nanostructured Coatings Co., Tehran, Iran). The coated samples were analysed using the SEM at an accelerating voltage of $15 \mathrm{kV}$.

\subsection{Storage Stability of Microcapsules}

The storage stability of microcapsules was evaluated via a 4-week storage trial. Samples were placed at a $50 \mathrm{~mL}$ centrifuge tubes and stored at 25 or $55^{\circ} \mathrm{C}$. The retention of carotenoids ( $\beta$-carotene, lutein, zeaxanthin), and $\omega$-3 LC-PUFAs (EPA, DHA) were determined at week 0 and week 4 .

\subsubsection{Determination of EPA and DHA}

EPA and DHA were determined according to Wei's method [21]. Briefly, $50 \mathrm{mg}$ of sample was weighed in a $15 \mathrm{~mL}$ centrifuge tube, and $50 \mu \mathrm{L}$ of internal standard methyl heptadecanoate $(30 \mathrm{mg} / \mathrm{mL})\left(\mathrm{C}_{18} \mathrm{H}_{36} \mathrm{O}_{2}\right)$ was added. Then, $2 \mathrm{~mL}$ of the concentrated sulphuric acid/methanol $(5 \%, v / v), 300 \mu \mathrm{L}$ of toluene and $25 \mu \mathrm{L}$ of BHT/methanol $(0.2 \%$, $w / w)$ were added into the mixture. The mixture was methylated at $92-95{ }^{\circ} \mathrm{C}$ for $1.5 \mathrm{~h}$. Afterwards, $2 \mathrm{~mL}$ of sodium chloride $(0.9 \%, w / w)$ and $2 \mathrm{~mL}$ of hexane was added for the extraction of the EPA and DHA methyl esters, which were then determined by gas chromatography (GC), coupled with a flame ionization detector (FID) (Agilent 7890N, Palo Alto, CA, USA) using a HP-FFAP column $(30 \mathrm{~m} \times 0.25 \mathrm{~mm} \times 0.25 \mu \mathrm{m}$, Agilent $\mathrm{J} \& \mathrm{~W}$ GC Columns).

Regarding the GC-FID conditions, nitrogen was used as the carrier gas at a flow rate of $20 \mathrm{~mL} / \mathrm{min}$. The oven temperature was set as below: initially at $150^{\circ} \mathrm{C}$; increased from $150{ }^{\circ} \mathrm{C}$ to $210{ }^{\circ} \mathrm{C}$ at $10^{\circ} \mathrm{C} / \mathrm{min}$; held for $7 \mathrm{~min}$; then increased to $230{ }^{\circ} \mathrm{C}$ at $20^{\circ} \mathrm{C} / \mathrm{min}$ and held for $6 \mathrm{~min}$. The injector temperature was $260^{\circ} \mathrm{C}$ and the split ratio was 30:1. Data were collected using the chemical station software (Agilent, Santa Clara, CA, USA). The concentrations of EPA and DHA were semi-quantified using the internal standard as a reference. 


\subsubsection{Characterization of Carotenoids}

Sample preparation for the determination of $\beta$-carotene, lutein and zeaxanthin was conducted according to AOAC method (2005.7). Firstly, $50 \mathrm{mg}$ of sample was dissolved in $10 \mathrm{~mL}$ of ethanol solution $(0.1 \% w / w$ BHT) and $10 \mathrm{~mL}$ of $\mathrm{KOH}$ solution $(10 \% w / w)$ was then added to the sample solution for saponification. The mixture was heated at $70{ }^{\circ} \mathrm{C}$ for $10 \mathrm{~min}$. After saponification, $10 \mathrm{~mL}$ of a combined petroleum ether and ethanol $(50 / 50 \%$, $v / v)$ solution was added to the mixture and vortexed for $3 \mathrm{~min}$. The above solution was further centrifuged at $4500 \mathrm{rpm} / \mathrm{min}$ for $5 \mathrm{~min}$. The supernatant was collected and the pellet was re-extracted with $10 \mathrm{~mL}$ of the petroleum ether and ethanol solution twice. The extracted oil phases were combined, and the excess solvent was removed under a gentle nitrogen flow. The obtained oil was dissolved in $1 \mathrm{~mL}$ of methanol for high performance liquid chromatography (HPLC) analysis.

Quantification of $\beta$-carotene was performed using an Agilent 1100 series system with a diode array detector-ultraviolent and visible (DAD UV-Vis) detector (Agilent 1260, Agilent Technologies, Santa Clara, CA, USA). A reversed phase C18 column $(4.6 \times 250 \mathrm{~mm}$, $4 \mu \mathrm{m}$, Phenomenex, Torrance, CA, USA) was used. The elution was performed with $98 \%$ methanol and $2 \%$ acetonitrile from 0 to $25 \mathrm{~min}$. Flow rate was $1.5 \mathrm{~mL} / \mathrm{min}$, detection wavelength was $450 \mathrm{~nm}$, and injection volume was $20 \mu \mathrm{L}$, and the temperature was $30{ }^{\circ} \mathrm{C}$. HPLC analysis for lutein and zeaxanthin was conducted according to previous studies [22,23], elution was performed with $15 \%$ methanol and $85 \%$ acetonitrile for $20 \mathrm{~min}$. Flow rate was $0.7 \mathrm{~mL} / \mathrm{min}$, detection wavelength was $450 \mathrm{~nm}$, injection volume was $20 \mu \mathrm{L}$, and the temperature was $30^{\circ} \mathrm{C}$.

\subsection{In Vitro Digestion of Microcapsules}

Microcapsules were subjected to in vitro digestion experiments simulating oral, gastric and intestinal conditions according to the method from Minekus et al. [24] with slight modification. At the oral phase, $2.5 \mathrm{~mL}$ of simulated saliva fluid (SSF) was added into a tube to solubilize a total of $0.5 \mathrm{~g}$ of the powder samples. The SSF was composed of SSF electrolyte stock solution $(70 \% v / v), \alpha$-amylase $(1500 \mathrm{U} / \mathrm{mL}, 10 \% v / v), 0.3 \mathrm{M} \mathrm{CaCl}_{2}(0.5 \%$ $v / v)$ and ultrapure water $(19.5 \% \mathrm{v} / \mathrm{v})$. The SSF electrolyte solution was constituted by $\mathrm{KCl}$ $(15.1 \mathrm{mmol} / \mathrm{L}), \mathrm{KH}_{2} \mathrm{PO}_{4}(3.7 \mathrm{mmol} / \mathrm{L}), \mathrm{NaHCO}_{3}(13.6 \mathrm{mmol} / \mathrm{L}), \mathrm{MgCl}_{2}(0.15 \mathrm{mmol} / \mathrm{L})$ and $\left(\mathrm{NH}_{4}\right)_{2} \mathrm{CO}_{3}(0.06 \mathrm{mmol} / \mathrm{L})$. The oral phase mixture was incubated at $37^{\circ} \mathrm{C}$ in a shaking water bath (Ratek, SWB20D, Australia) for $2 \mathrm{~min}$.

At gastric phase, the oral bolus was added by $2.5 \mathrm{~mL}$ of simulated gastric fluid (SGF) consisting of SGF electrolyte stock solution $(75 \% v / v)$, pepsin $(25,000 \mathrm{U} / \mathrm{mL}, 16 \% v / v)$, $0.3 \mathrm{M} \mathrm{CaCl}_{2}(0.05 \% v / v)$, ultrapure water $(4.55 \% v / v)$ and $1 \mathrm{~mol} / \mathrm{L} \mathrm{HCl}(4.4 \% v / v)$. The SGF electrolyte solution contained $\mathrm{KCl}(6.9 \mathrm{mmol} / \mathrm{L}), \mathrm{KH}_{2} \mathrm{PO}_{4}(0.9 \mathrm{mmol} / \mathrm{L}), \mathrm{NaHCO}_{3}$ $(25 \mathrm{mmol} / \mathrm{L}), \mathrm{NaCl}(47.2 \mathrm{mmol} / \mathrm{L}), \mathrm{MgCl}_{2}(0.1 \mathrm{mmol} / \mathrm{L})$, and $\left(\mathrm{NH}_{4}\right)_{2} \mathrm{CO}_{3}(0.5 \mathrm{mmol} / \mathrm{L})$. The $\mathrm{pH}$ of the gastric mixture was adjusted to 3 by $6 \mathrm{~mol} / \mathrm{L} \mathrm{HCl}$. The mixture was incubated for $2 \mathrm{~h}$ at $37^{\circ} \mathrm{C}$. For the intestinal phase, $5 \mathrm{~mL}$ of simulated intestinal fluid (SIF) was added to gastric digestion mixture for further intestinal digestion. The SIF was comprised of SIF electrolyte stock solution ( $55 \% v / v)$, pancreatic lipase solution $(1200 \mathrm{U} / \mathrm{mL}, 25 \% v / v)$, bile salt solution $(8 \mathrm{mg} / \mathrm{mL}, 12.5 \% v / v), 0.3 \mathrm{M} \mathrm{CaCl}_{2}(0.2 \% v / v)$, ultrapure water $(0.75 \% v / v)$, and its $\mathrm{pH}$ was adjusted to 7 with $1 \mathrm{~mol} / \mathrm{L} \mathrm{NaOH}(6.55 \% \mathrm{v} / \mathrm{v})$. The SIF electrolyte stock solution was constituted by $\mathrm{KCl}(6.8 \mathrm{mmol} / \mathrm{L}), \mathrm{KH}_{2} \mathrm{PO}_{4}(0.8 \mathrm{mmol} / \mathrm{L}), \mathrm{NaHCO}_{3}(85 \mathrm{mmol} / \mathrm{L}), \mathrm{NaCl}$ $(38.4 \mathrm{mmol} / \mathrm{L})$, and $\mathrm{MgCl}_{2}(0.33 \mathrm{mmol} / \mathrm{L})$. The mixed sample was incubated at $37^{\circ} \mathrm{C}$ for $2 \mathrm{~h}$ in a shaking incubator.

\subsection{Digesta Analysis}

\subsubsection{Droplet Size}

The average droplet size of digesta solution from each digestion phase was determined following the same method as described in Section 2.4.4. 


\subsubsection{Zeta Potential}

The zeta potential of digesta solution from each digestion phase was measured using a Zetasizer Nano ZS (Malvern, Herrenberg, Germany). The diluted sample was injected into a capillary cell (Malvern, Herrenberg, Germany), and was measured at $25^{\circ} \mathrm{C}$ in the measurement chamber.

\subsubsection{Digestion Behaviours}

The microstructure of the dried digesta from gastric and intestinal phase was examined by SEM as mentioned in Section 2.5. The digesta after gastric and intestinal phase was also observed by confocal scanning laser microscopy (CSLM) (Olympus FV 1000, Tokyo, Japan) according to Lueamsaisuk's method [25]. Aliquots from each sample were stained with $5 \mu \mathrm{L}$ of aqueous Nile Blue $(1 \%, w / w)$. The subsample was placed on a microscopy slide with a cover slip. The confocal images were obtained using 10x objective lens. The oil phase was excited with an Argon laser light at $473 \mathrm{~nm}$. The confocal images were acquired by Olympus Fluoview (Viewer 4.2b, Olympus, Japan).

\subsection{Statistical Analysis}

All experiments were conducted in triplicate. Results were expressed as mean \pm standard deviation for each sample. One-way ANOVA was used to analyse the data using SPSS Statistics (Version 19, IBM, Armonk, NY, USA). Significance level was determined at $p<0.05$ (Post hoc test: Duncan's test).

\section{Results and Discussion}

\subsection{Microstructure of Microcapsules}

Representative SEM photos of microcapsules produced by three drying methods, FD, SD, and MFJSD, were shown in Figure 2. Overall, the microcapsules obtained by FD (Figure 2; B1, B2, B3) were significantly different from those acquired from SD and MFJSD (Figure 2; A1, A2, A3 and $\mathrm{C} 1, \mathrm{C} 2, \mathrm{C} 3$, respectively) regarding the particle morphology. The freeze-dried microcapsules showed an irregular and fragmented morphology rather than spherical morphologies seen from the spray-dried powders, and this could be due to the friability of the freeze-dried products.

The MFJSD microcapsules $(\mathrm{C} 1, \mathrm{C} 2, \mathrm{C} 3)$ generally presented identical particle sizes and a good uniformity in morphological characteristics, while the SD microcapsules (A1, A2, A3) showed a wide range of particle size distribution and irregular surface morphologies. Such differences were mostly attributed to the atomization characteristics of the two spraying drying equipment. The atomization of traditional spray dryer is based on a pneumatic nozzle atomizer, which is prone to produce practices with poor homogeneity. However, the MFJSD is equipped with a monodisperse droplet generator, which can produce microcapsules with a good uniformity in both particle size and morphology. It is also noted that the particle size of MFJSD microcapsules $(\sim 100 \mu \mathrm{m})$ was much larger than that of SD microcapsules $(<10 \mu \mathrm{m})$ (Figure 2). This result is in agreement with previous findings that the average droplet diameter of MFJSD with an electro-hydrodynamic droplet generator $(E H D G)$ is roughly twice the liquid jet diameter or orifice diameter $(75 \mu \mathrm{m})$ [26], and the size range of particles produced by two fluid nozzle atomizers is 1-30 $\mu \mathrm{m}$ [27]. Huang et al. [16] also reported that MFJSD microcapsules encapsulated by OSA modified starch showed a particle size ranging between 110 and $180 \mu \mathrm{m}$, which was around 10 times larger than those produced by conventional spray dryers [28].

As the droplets were monodispersed by MFJSD, resulting in a minimised aggregation of the powders, the morphology differences among the MFJSD microcapsules $(\mathrm{C} 1, \mathrm{C} 2$, C3) with different wall materials were easily to be observed. For example, the MFJSD-W sample showed round and smooth particle surface with large indents, while the MFJSD-O powder presented irregular surfaces with apparent shrinkage and wrinkles. This could be caused by the different rate of surface crust formation during spray-drying process. It is reported that the OSA emulsion had slower rate of crust formation than the WPI emulsion 
during the drying process $[29,30]$, and a slower rate of crust formation normally leads to a greater extent of droplet shrinkage before the complete solidification of surface wall and, thus, resulting in more dents and wrinkles on the particle surface [26,27]. Moreover, the morphology of the MFJSD-WO sample was similar to that of the MFJSD-W, both of them presented round and smooth surfaces with large indents. This indicated that WPI had a greater influence on particle morphology than OSA, as the wall material composition of the MFJSD-WO sample was 50\% WPI and 50\% OSA.
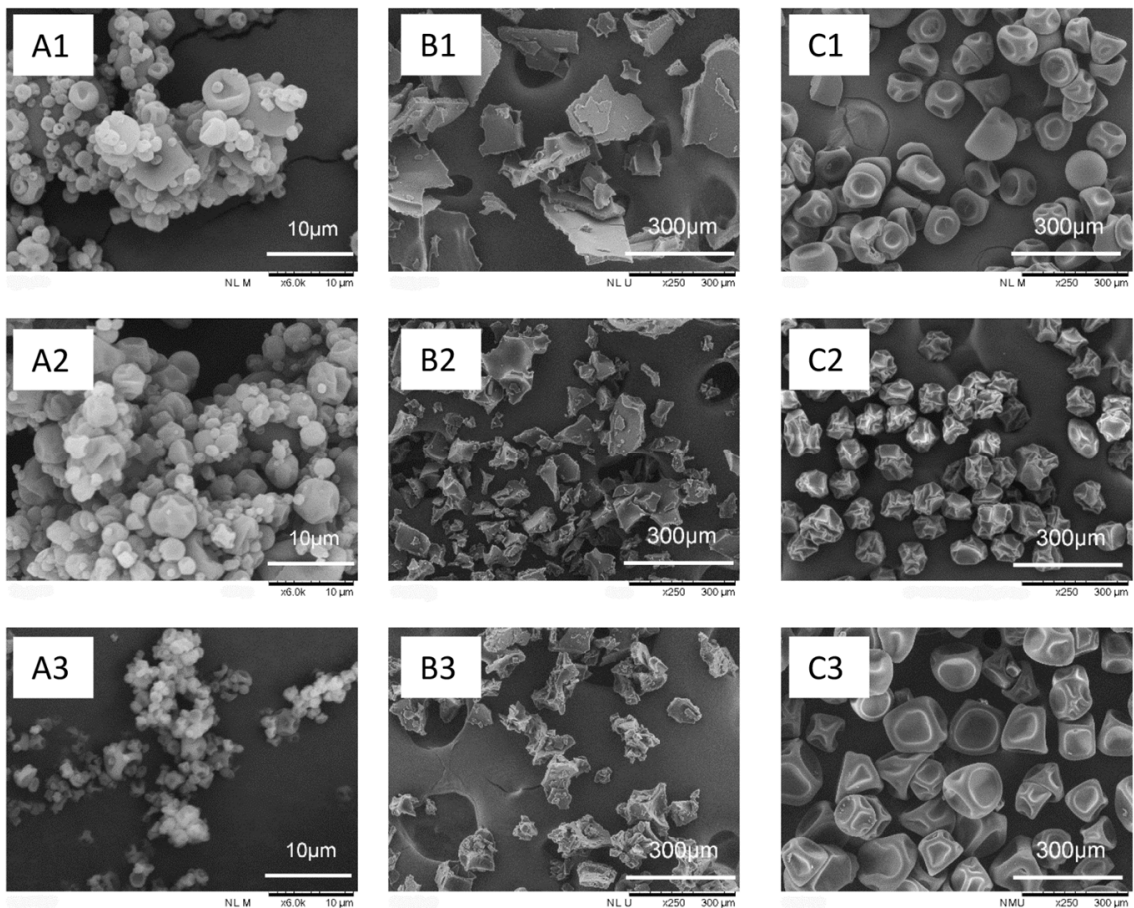

Figure 2. Microstructure of microcapsules. (A1) SD-W, (A2) SD-O, (A3) SD-WO at 6000× magnification; (B1) FD-W, (B2) FD-O, (B3) FD-WO at 250× magnification; (C1) MFJSD-W, (C2) MFJSD-O, (C3) MFJSD-WO at 250× magnification. SD-W, SD-O, and SD-WO: microcapsules produced by twofluid nozzle spray drying, using WPI only, OSA only, and a combination of WPI/OSA (50/50 w/w) as wall materials, respectively; FD-W, FD-O, and FD-WO: microcapsules produced by freeze-drying, using WPI only, OSA only, and a combination of WPI/OSA (50/50 w/w), as wall materials, respectively; MFJSD-W, MFJSD-O, and MFJSD-WO: microcapsules produced by microfluidic-jet spray drying, using WPI only, OSA only, and a combination of WPI/OSA (50/50 w/w) as wall materials, respectively. WPI: whey protein isolate; OSA: octenylsuccinic anhydride modified starch.

\subsection{Physicochemical Properties of Microcapsules}

\subsubsection{Water Activity $\left(\mathrm{a}_{\mathrm{w}}\right)$}

In Table 1 , the $\mathrm{a}_{\mathrm{w}}$ range for the microcapsules obtained by each drying technique was $0.241-0.264,0.234-0.280$, and $0.229-0.260$ for the SD, FD, and MFJSD samples, respectively. Powder products with $\mathrm{a}_{\mathrm{w}}$ below 0.6 are generally considered microbial safe; therefore, all microcapsules in this study had high stability against microbial growth. This also suggested that all the three drying techniques employed in this study could achieve good drying performance with a desirable $\mathrm{a}_{\mathrm{w}}$ value. The microcapsules encapsulated by WPI-only showed higher $\mathrm{a}_{\mathrm{w}}$ (0.264 for SD-W, 0.280 for FD-W, 0.260 for MFJSD-W) than the OSA microcapsules (0.241 for SD-O, 0.234 for FD-O, 0.229 for MFJSD-O). This may be due to the stronger water binding capacity of OSA modified starch compared to WPI. Yan, et al. [31] reported that high levels of OSA modified starch facilitate the water binding capacity of the oil-in-water emulsion. The lower $\mathrm{a}_{\mathrm{w}}$ of OSA microcapsules may also result from the high-water binding capacity. 


\subsubsection{Microencapsulation Efficiency (ME)}

As shown in Table 1, the MFJSD microcapsules had the highest ME (94.0-95.1\%) followed by the SD samples (84.4-91.7\%), and the ME of the FD samples was the lowest (69.9-77.3\%) among all. The differences in ME may be related to the morphological characteristics of the microcapsules. The low ME of freeze-dried microcapsules was possibly caused by the high porosity of the particles, which resulted from the sublimation of ice crystals from the inner structure of the frozen samples during freeze-drying.

Compared to the freeze-dried products, spray-dried products showed a higher encapsulation efficiency, which is possibly due to their different drying principles. Specifically, during spray drying, the droplets are ejected into a drying chamber with immediate contact to high temperature air. This process causes instant water evaporation and then solute condensation, which eventually forms a compact and rigid crust for encapsulating the core materials [32]. In addition, the ME of the MFJSD microcapsules was greater than that of the SD microcapsules. This may be related to their particle size. The particle size of the MFJSD microcapsules was much larger than that of the SD microcapsules. Thus, due to a smaller total surface area from a larger particle size, less oil shall present on the surface of the MFJSD microcapsules, resulting in higher ME.

Table 1. Physicochemical properties of microcapsules.

\begin{tabular}{ccccc}
\hline Samples & Water Activity & ME (\%) & Tapped Density $\left(\mathbf{g} / \mathbf{c m}^{3}\right)$ & Carr Index (\%) \\
\hline SD-W & $0.264 \pm 0.002^{\mathrm{bc}}$ & $84.4 \pm 0.1^{\mathrm{b}}$ & $0.27 \pm 0.01^{\mathrm{d}}$ & $44.6 \pm 3.0^{\mathrm{a}}$ \\
SD-O & $0.241 \pm 0.010^{\mathrm{bcd}}$ & $91.7 \pm 0.2^{\mathrm{a}}$ & $0.46 \pm 0.02^{\mathrm{b}}$ & $41.0 \pm 3.7^{\mathrm{a}}$ \\
SD-WO & $0.260 \pm 0.000^{\mathrm{abc}}$ & $85.4 \pm 1.8^{\mathrm{b}}$ & $0.32 \pm 0.00^{\mathrm{cd}}$ & $48.4 \pm 1.4^{\mathrm{a}}$ \\
FD-W & $0.280 \pm 0.008^{\mathrm{a}}$ & $69.9 \pm 4.9^{\mathrm{d}}$ & $0.32 \pm 0.01^{\mathrm{cd}}$ & $34.1 \pm 1.4^{\mathrm{b}}$ \\
FD-O & $0.234 \pm 0.028^{\mathrm{cd}}$ & $77.3 \pm 3.8^{\mathrm{c}}$ & $0.39 \pm 0.00^{\mathrm{c}}$ & $34.0 \pm 2.5^{\mathrm{b}}$ \\
FD-WO & $0.236 \pm 0.010^{\mathrm{cd}}$ & $74.3 \pm 0.2^{\mathrm{cd}}$ & $0.33 \pm 0.02^{\mathrm{cd}}$ & $43.1 \pm 6.5^{\mathrm{a}}$ \\
MFJSD-W & $0.260 \pm 0.001^{\mathrm{bc}}$ & $94.0 \pm 1.5^{\mathrm{a}}$ & $0.46 \pm 0.01^{\mathrm{b}}$ & $30.0 \pm 1.0^{\mathrm{b}}$ \\
MFJSD -O & $0.229 \pm 0.006^{\mathrm{d}}$ & $94.1 \pm 0.6^{\mathrm{a}}$ & $0.65 \pm 0.01^{\mathrm{a}}$ & $19.2^{\mathrm{c}} \pm 1.0^{\mathrm{c}}$ \\
MFJSD-WO & $0.231 \pm 0.004^{\mathrm{d}}$ & $95.1 \pm 0.7^{\mathrm{a}}$ & $0.37 \pm 0.03^{\mathrm{c}}$ & $16.0 \pm 2.7^{\mathrm{c}}$ \\
\hline
\end{tabular}

SD-W, SD-O, and SD-WO: microcapsules produced by two-fluid nozzle spray drying, using WPI only, OSA only, and a combination of WPI/OSA $(50 / 50 w / w)$ as wall materials, respectively; FD-W, FD-O, and FD-WO: microcapsules produced by freeze-drying, using WPI only, OSA only, and a combination of WPI/OSA (50/50 w/w) as wall materials, respectively; MFJSD-W, MFJSD-O, and MFJSD-WO: microcapsules produced by microfluidicjet spray drying, using WPI only, OSA only, and a combination of WPI/OSA (50/50 w/w) as wall materials, respectively. WPI: whey protein isolate; OSA: octenylsuccinic anhydride modified starch. ME: microencapsulation efficiency; Different letters in superscript for each column indicate significant differences at $p<0.05$.

\subsubsection{Density and Flowability}

The tapped densities of the MFJSD microcapsules $\left(0.37-0.65 \mathrm{~g} / \mathrm{cm}^{3}\right)$ were higher than those of the SD $\left(0.27-0.46 \mathrm{~g} / \mathrm{cm}^{3}\right)$ and FD microcapsules $\left(0.32-0.39 \mathrm{~g} / \mathrm{cm}^{3}\right)$ (Table 1). A low density for powder products generally indicates significant amount of occluded air in the interspace between particles. Literature has also reported that, due to the pneumatic nozzle atomizer, two-fluid nozzle spray dryer is prone to produce particles with high occluded air [32]. Moreover, as mentioned before, the MFJSD microcapsules were over ten-fold larger than the SD microcapsules [33]; therefore, less occluded air would exist in the MFJSD particles, resulting in a higher density of the powders. A low density with more air among particles could also lead to a high risk of oxidation that affects storage stability of powder products. Based on this, the MFJSD microcapsules with a relatively higher powder density were considered more stable during storage.

However, our results on density were not consistent with the findings from Elversson and Millqvist-Fureby [34], who reported a higher density from the spray-dried microcapsules with smaller particle sizes. However, the size difference among their samples produced using different wall materials (approximately 35\% to 55\%) were much smaller compared to the large size variation (more than 10 times) in our samples. Therefore, the phenomenon in this study could be distinctive, and may require further investigation. 
The SD microcapsules showed a higher Carr index (41.0-48.4\%) than the MFJSD microcapsules (16.0-30.0\%) (Table 1), indicating that the MFJSD microcapsules had a better flowability than the SD microcapsules. The poor flowability of SD microcapsules also can be confirmed by the significantly agglomerated particles, as shown in Figure 1, in the SD microcapsules (A1, A2, A3). In contrast, the MFJSD particles $(C 1, C 2, C 3)$ were well separated and non-agglomerated (Figure 1). Generally, microcapsules with a small particle size would result in a poor flowability because of large surface area per mass unit. The increases on surface area lead to strengthened cohesion and attrition force and result in a flow resistance between particle-particle or particle-container [35]. Furthermore, the irregular droplet trajectories of the SD microcapsules could be another reason for the poor flowability as it can cause complex collisions between particles and/or between particle and the interior dryer surface. Therefore, the MFJSD, equipped with monodisperse droplet generator to produce single stream droplets with similar droplet trajectories and drying paths, could produce microcapsules with enhanced flowability.

Compared to the microcapsules produced by SD and MFJSD, the FD microcapsules had a relatively high Carr index ( $>34 \%$ ) probably due to the irregular particle shape and high surface oil present on the surface of the particles. As reported previously in Section 3.2.2, FD microcapsules had a low ME, thereby a high amount of surface oil, which leads to viscous surface and increases attrition force between particles.

\subsubsection{Particle Size}

As shown in Figure 3, the reconstituted emulsions from the MFJSD microcapsules (MFJSD-W, MFJSD-O, MFJSD-WO) presented a unimodal distribution, which was close to its corresponding initial emulsion. While the SD microcapsules (SD-W, SD-WO) and the FD microcapsules (FD-W, FD-WO) showed a bimodal distribution or multimodal distribution after reconstitution. Consistently, compared to the SD and FD microcapsules, the MFJSD microcapsules, after reconstitution, had a droplet size (229.8 nm for MFJSD-W, $297.9 \mathrm{~nm}$ for MFJSD-O, and $255.2 \mathrm{~nm}$ for MFJSD-WO) much closer to the initial emulsion (210.3 nm for WPI emulsion, $297.0 \mathrm{~nm}$ for OSA emulsion, and $245.3 \mathrm{~nm}$ for WO emulsion).

In addition, the PDI of the three initial emulsions ranged from 0.230 to 0.261 . The MFJSD microcapsules showed a smaller range of PDI in their reconstituted emulsions (0.208-0.300) than the SD microcapsules (0.236-0.485) and the FD microcapsules (0.160-0.503) (Figure 3). These results indicate that the MFJSD microcapsules had a better reconstitution property than the other two kinds of microcapsules. The reason for this phenomenon may be attributed to the good uniformity of MFJSD microcapsules in particle size and morphology. Moreover, it is noted that all OSA microcapsules (SD-O, FD-O, MFJSD-O) showed a unimodal distribution, which was close to the OSA emulsion, suggesting that OSA modified starch is a reliable wall material with good stability and solubility in the reconstitution process regardless of drying methods.

\subsection{Storage Stability of Microcapsules}

After a 4 -week storage at $55^{\circ} \mathrm{C}$, the retention of carotenoids and $\omega$-3 PUFAs in SD-O microcapsules was lower than that in FD-O and MFJSD-O microcapsules (Figure 4). For example, the retention of $\beta$-carotene in the SD microcapsules after 4 weeks was $44.5 \%$, which was lower than that in the FD (59.7\%) and MFJSD microcapsules (53.3\%). The possible reason would be due to a small particle size and large surface area of the SD particles, which increased the possibility of compound degradation/oxidation, as well as the undesired chemical reactions with external substances. Studies have reported that spray-dried powders with a smaller particle size and higher surface areas showed a faster degradation kinetics due to a higher dissolution rate of the embedded active components in larger exposure areas [36,37]. 


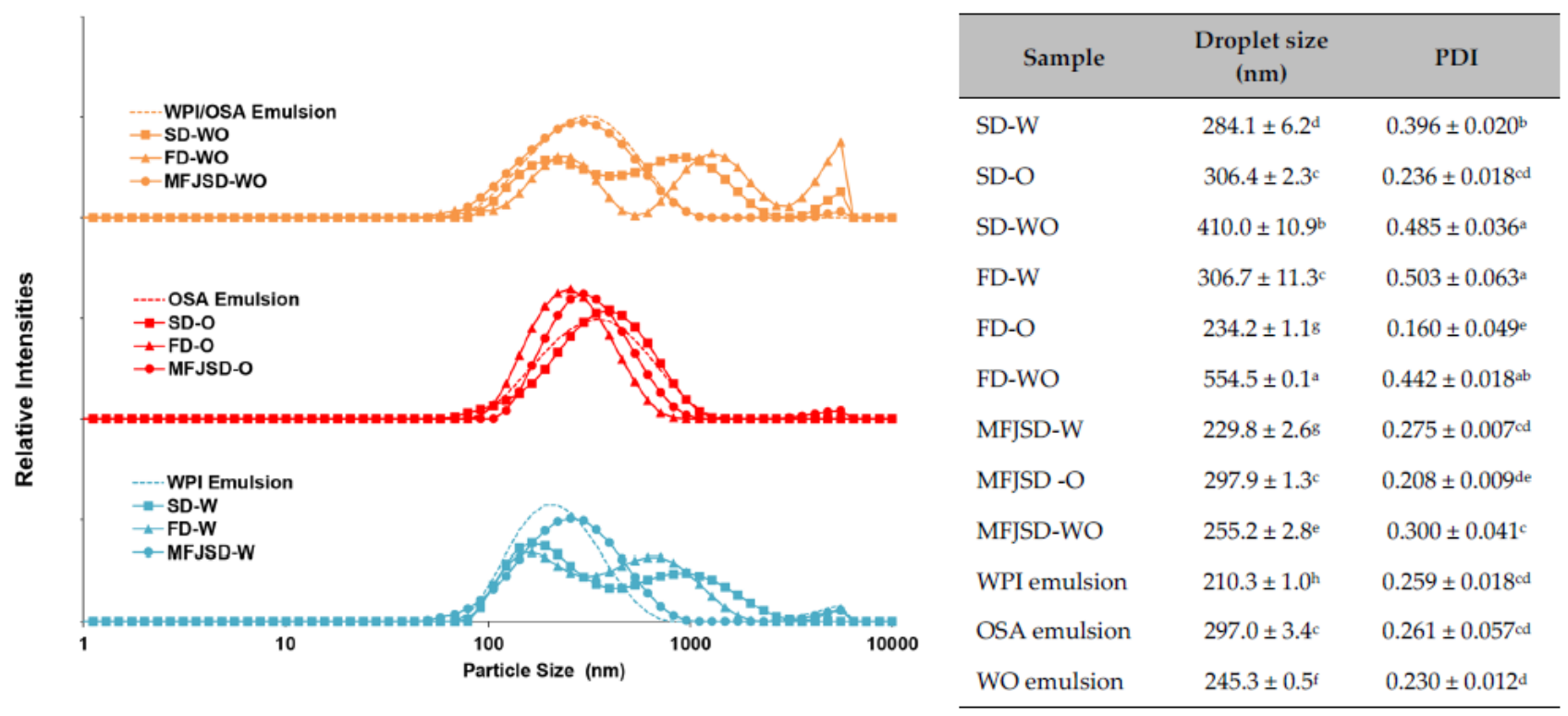

Figure 3. Particle size distribution of the initial and reconstituted emulsions. SD-W, SD-O, and SD-WO: microcapsules produced by two-fluid nozzle spray drying, using WPI only, OSA only, and a combination of WPI/OSA (50/50 w/w) as wall materials, respectively; FD-W, FD-O, and FD-WO: microcapsules produced by freeze-drying, using WPI only, OSA only, and a combination of WPI/OSA $(50 / 50 w / w)$ as wall materials, respectively; MFJSD-W, MFJSD-O, and MFJSD-WO: microcapsules produced by microfluidic-jet spray drying, using WPI only, OSA only, and a combination of WPI/OSA $(50 / 50 w / w)$ as wall materials, respectively. WPI: whey protein isolate; OSA: octenylsuccinic anhydride modified starch. WO: a combination of WPI and OSA (50/50 w/w). PDI: particle size distribution index. Different letters in superscript for each column indicate significant differences at $p<0.05$.

From Figure 4, the MFJSD microcapsules stored at $25^{\circ} \mathrm{C}$ had much higher retentions of carotenoids and $\omega$-3 PUFAs than those stored at $55^{\circ} \mathrm{C}$, after 4 -week storage. Due to the highly unsaturated chemical structure, carotenoids are prone to degrade into volatile and non-volatile compounds when exposed to thermal stress especially in the presence of oxygen. The polyene molecule can be attacked by oxygen either on the $\beta$-ring or on the chain and subsequently form the initial oxidation products-epoxides $[38,39]$. Similarly, due to the presence of numerous methylene-interrupted ethylenic double bonds, EPA and DHA are sensitive to heat treatment and could be subjected to a number of chemical transformations, including oxidation, polymerization, cyclization, and double bond migration [40]. In conclusion, MFJSD and FD could provide better protection to bioactive core materials than SD, and both carotenoids and $\omega-3$ PUFAs showed a higher stability at a lower storage temperature.

\subsection{In Vitro Digestion Behaviours of Microcapsules}

As can be seen in Figure 5, the particle size of all samples started to increase from oral digestion to gastric digestion, and decreased after intestinal digestion. Particularly, all samples presented a significant increase $(p<0.05)$ of particle size after gastric digestion. Further, after intestinal digestion, the particle size of all samples, although still larger than the initial emulsions, showed a significant decrease $(p<0.05)$.

The slight changes on the particle size after the digestion in oral phase could be due to the altered ionic strength and $\mathrm{pH}$ value in samples [41]. Furthermore, the markedly increase of the particle size diameter after a subsequent digestion in the stomach phase resulted from the changes in $\mathrm{pH}$ and ionic strength, as well as the effect of the hydrolysed products from the adsorbed proteins and polysaccharides [42,43]. The low $\mathrm{pH}$ in the stomach phase caused a decrease of the absolute zeta potential on emulsion droplets, which led to the aggregation of droplets by weakening the electrostatic repulsion force. 
(a)

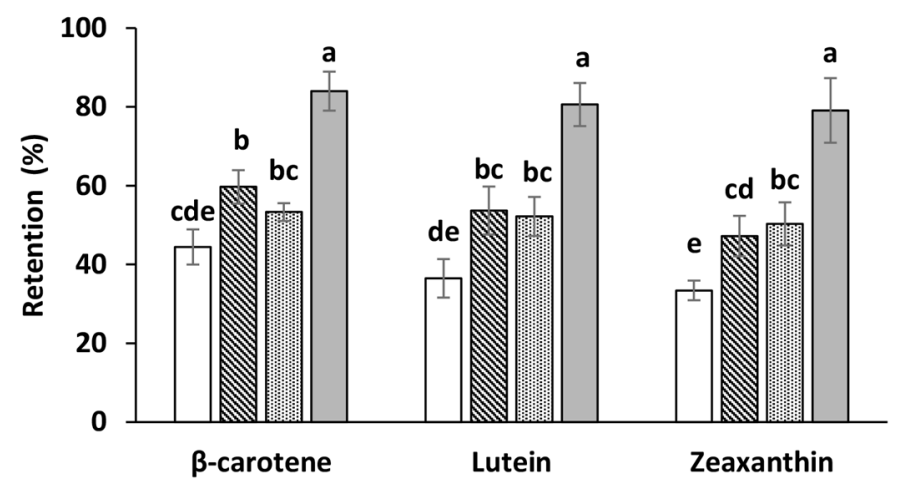

$\square \mathrm{SD}-\mathrm{O} / 55^{\circ} \mathrm{C}$

$\mathbb{F D}-0 / 55^{\circ} \mathrm{C}$

圈 MFJSD-O $/ 55^{\circ} \mathrm{C}$

$\square$ MFJSD- $0 / 25^{\circ} \mathrm{C}$

(b)

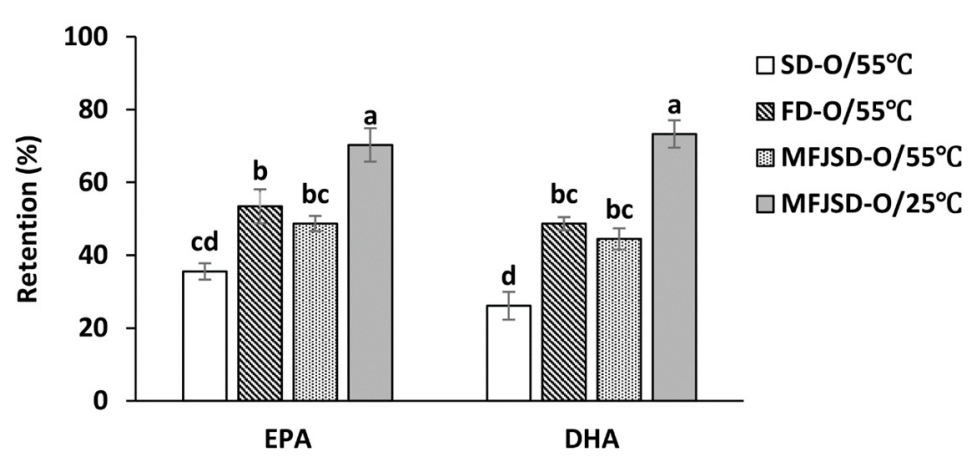

Figure 4. Retentions of (a) $\beta$-carotene, lutein, zeaxanthin and (b) EPA, DHA after a 4-week period at $25^{\circ} \mathrm{C}$ and $55^{\circ} \mathrm{C}$. SD-O: microcapsules produced by two-fluid nozzle spray drying, using OSA only as wall material; FD-O: microcapsules produced by freeze-drying, using OSA only as wall material; MFJSD-O: microcapsules produced by microfluidic-jet spray drying, using OSA only as wall material. WPI: whey protein isolate; OSA: octenylsuccinic anhydride modified starch. Different lowercase letters indicate significant differences at $p<0.05$.

Another reason for droplet size increase was due to the presence of pepsin and $\alpha$-amylase in the digestion system. After WPI and OSA modified starch underwent enzymolysis, their chemical structures were altered and their emulsifying abilities were weakened, which led to the occurrence of agglomeration and, thereby, the increase of droplet size. After digestion in the intestinal phase, the particle size of all samples showed a decrease compared to that in the stomach phase. This may be due to the increase of $\mathrm{pH}$, and effect from the lipid hydrolysis by pancreatin and bile salts in the system. The increase of $\mathrm{pH}$ would result in a larger absolute zeta potential on droplets and, thereby, a stronger electrostatic repulsion force to keep droplets from aggregation or coalescence, finally leading to the decrease of droplet size [44].

After passing through the intestinal phase, the MFJSD-O sample showed a larger droplet size diameter $(1410.5 \mathrm{~nm})$ than the MFJSD-W $(843.0 \mathrm{~nm})(p>0.05)$. The difference in the droplet size between these two MFJSD microcapsules after the intestinal digestion was mainly due to the different polymer properties of the two wall materials, WPI and OSA. There was a difference in zeta potential of digested emulsions between MFJSD-O and MFJSD-W. In Figure 6, the absolute zeta potential of the MFJSD-O sample after intestinal digestion was $28.3 \mathrm{mV}$, which was lower than that of the MFJSD-W $(40.6 \mathrm{mV})$. As reported by previous studies, the presence of electrical charges on droplet surface may contribute to a strong electrical repulsion to prevent droplets against aggregation and flocculation [45,46].

Moreover, there was no significant difference $(p>0.05)$ in droplet size of emulsions after the intestinal digestion among MFJSD-O, SD-O, and FD-O (Figure 5). This phenomenon 
may be explained by the fact that the three samples were dried from the same original emulsion, which is very likely to be digested at a comparable degree reflecting a similar droplet size of the final digested emulsions.

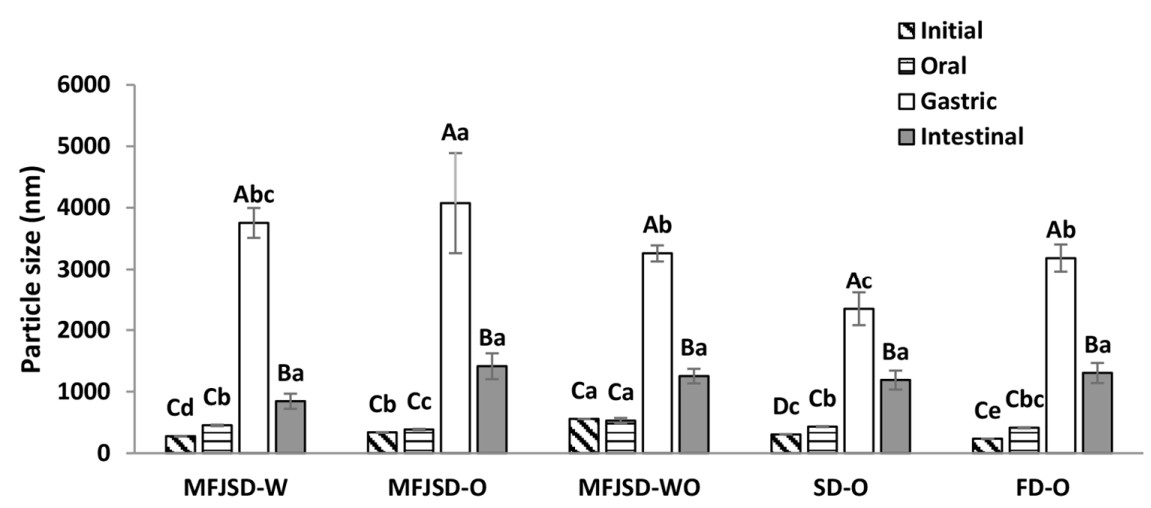

Figure 5. The particle size changes of the microcapsules after in vitro digestion. MFJSD-W, MFJSD-O, and MFJSD-WO: microcapsules produced by microfluidic-jet spray drying, using WPI only, OSA only, and a combination of WPI/OSA $(50 / 50 w / w)$ as wall materials, respectively; SD-O: microcapsules produced by two-fluid nozzle spray drying, using OSA only as wall material; FD-O: microcapsules produced by freeze-drying, using OSA only as wall material; WPI: whey protein isolate; OSA: octenylsuccinic anhydride modified starch. The lowercase letters indicate significant difference in different samples with the same digestion phase $(p<0.05)$; the uppercase letters indicate significant difference in same sample $(p<0.05)$.

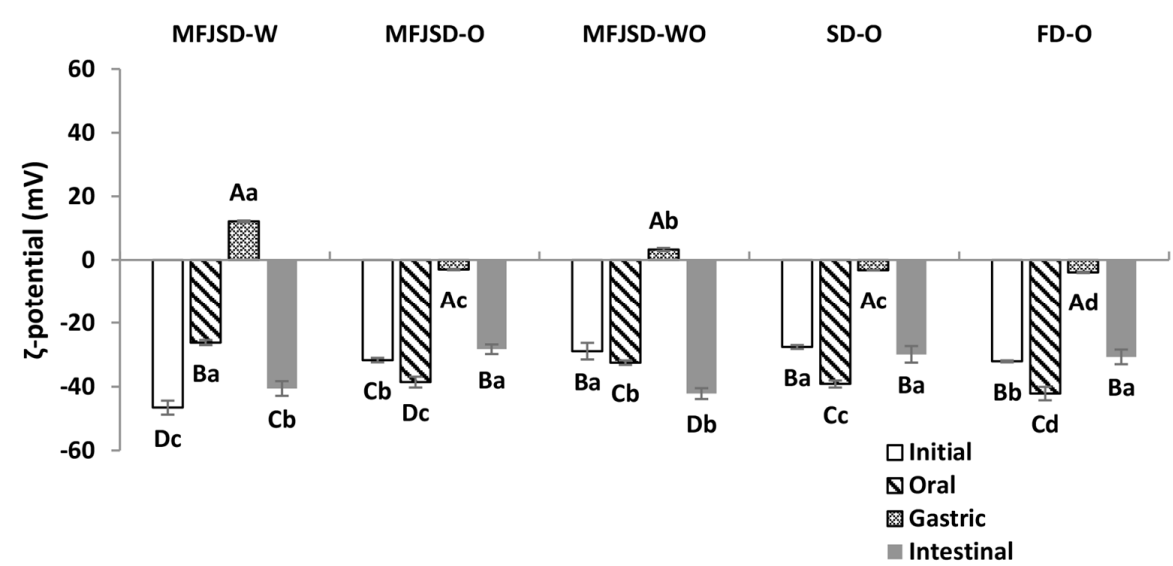

Figure 6. Zeta potential of microcapsules after in vitro digestion. MFJSD-W, MFJSD-O, and MFJSDWO: microcapsules produced by microfluidic-jet spray drying, using WPI only, OSA only, and a combination of WPI/OSA (50/50 w/w) as wall materials, respectively; SD-O: microcapsules produced by two-fluid nozzle spray drying, using OSA only as wall material; FD-O: microcapsules produced by freeze-drying, using OSA only as wall material; WPI: whey protein isolate; OSA: octenylsuccinic anhydride modified starch. The lowercase letters indicate significant difference in different samples with the same digestion phase $(p<0.05)$; the uppercase letters indicate significant difference in same sample $(p<0.05)$.

It can be seen from Figure 7 that after the gastric digestion, the MFJSD-W sample retained its spherical shape under the effect of protease (pepsin), but the surface of the MFJSD-W sample decomposed from a relatively smooth surface into a rough surface. There were also some digested particles in randomised sizes attached on its spherical surface. For the samples containing OSA modified starch (MFJSD-O, MFJSD-WO, SD-O, FD-O), they all lost their spherical shape (Figure 7) due to the effect of amylase, and after gastric digestion, the shape were further reorganised and became irregular. 
After further digestion in the simulated intestines (Figure 8), the MFJSD-W sample finally lost its original spherical shape because of the effect of protease contained in the pancreatin, which had further digested and decomposed whey proteins in the MFJSD-W sample. On the other hand, there were more holes appearing on the surface of the OSAcontaining particles after the intestinal digestion. These pores may be due to the digestion effect of amylase in the added pancreatin, contributing to the release of oil droplets to the surface of the particles.

Moreover, the MFJSD sample, containing WPI (MFJSD-W), showed a sharper and crumbly morphology compared to the samples containing OSA modified starch (MFJSD$\mathrm{O}, \mathrm{MFJSD}-\mathrm{WO}, \mathrm{SD}-\mathrm{O}, \mathrm{FD}-\mathrm{O}$ ) after intestinal digestion (Figure 8). This may be because the dried particles containing whey proteins tend to have a hard crust surface with a low elasticity [29]. To the contrary, the particle surface of the OSA-containing samples presented as more rounded and softer, which may be due to the high elasticity of OSA modified [47].

$100 \times$
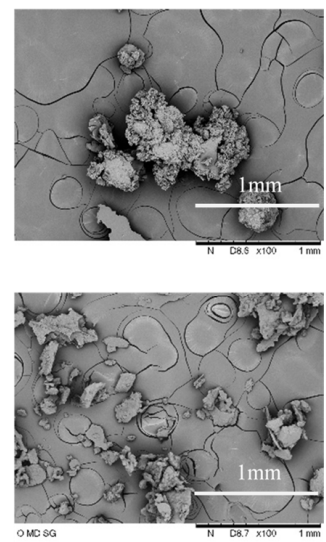

MFJSD-O

MFJSD-W
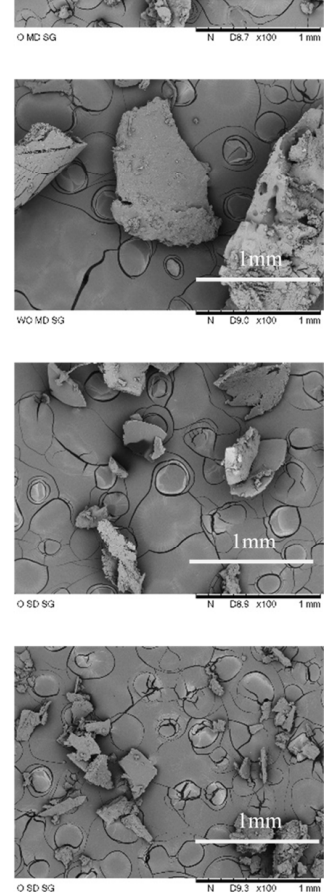

$800 \times$
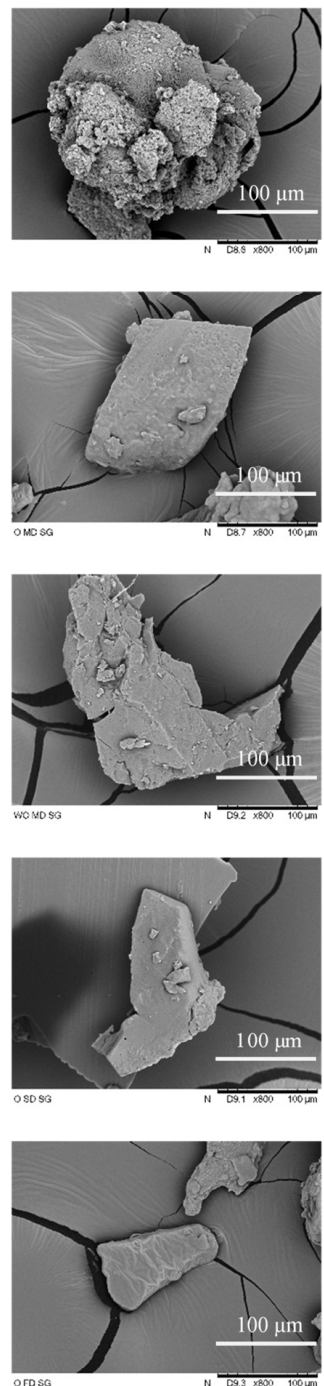

$2000 \times$
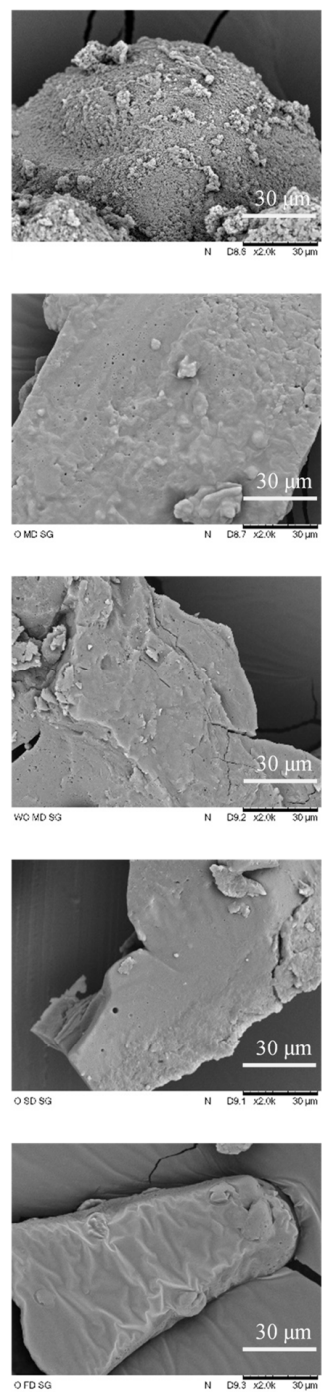

Figure 7. Microstructure of microcapsules after simulated gastric digestion (magnification: $100 \times$, $800 \times, 2000 \times$ ). MFJSD-W, MFJSD-O, and MFJSD-WO: microcapsules produced by microfluidic-jet spray drying, using WPI only, OSA only, and a combination of WPI/OSA $(50 / 50 w / w)$ as wall materials, respectively; SD-O: microcapsules produced by two-fluid nozzle spray drying, using OSA only as wall material; FD-O: microcapsules produced by freeze-drying, using OSA only as wall material; WPI: whey protein isolate; OSA: octenylsuccinic anhydride modified starch. 
$100 \times$
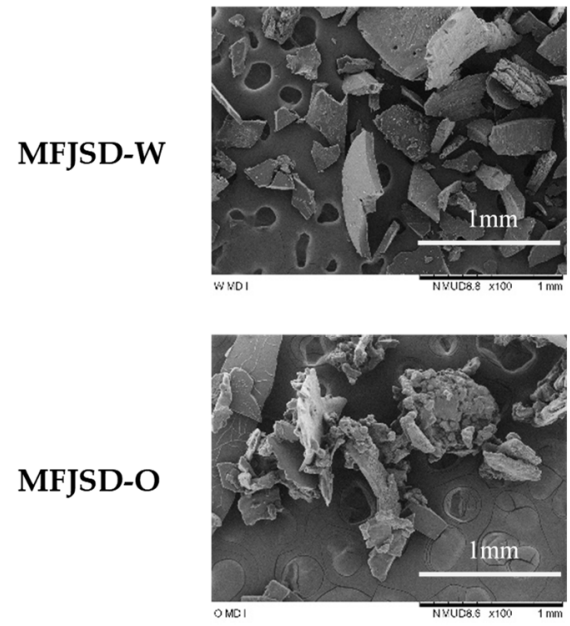

MFJSD-O

MFJSD-

WO

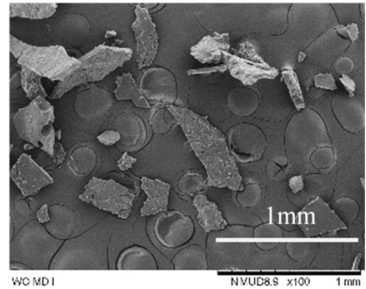

SD-O
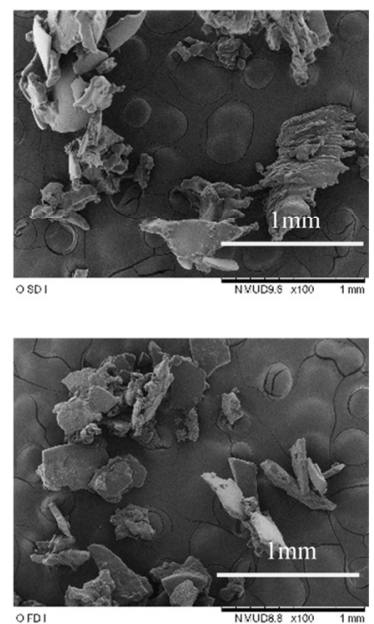

$800 \times$
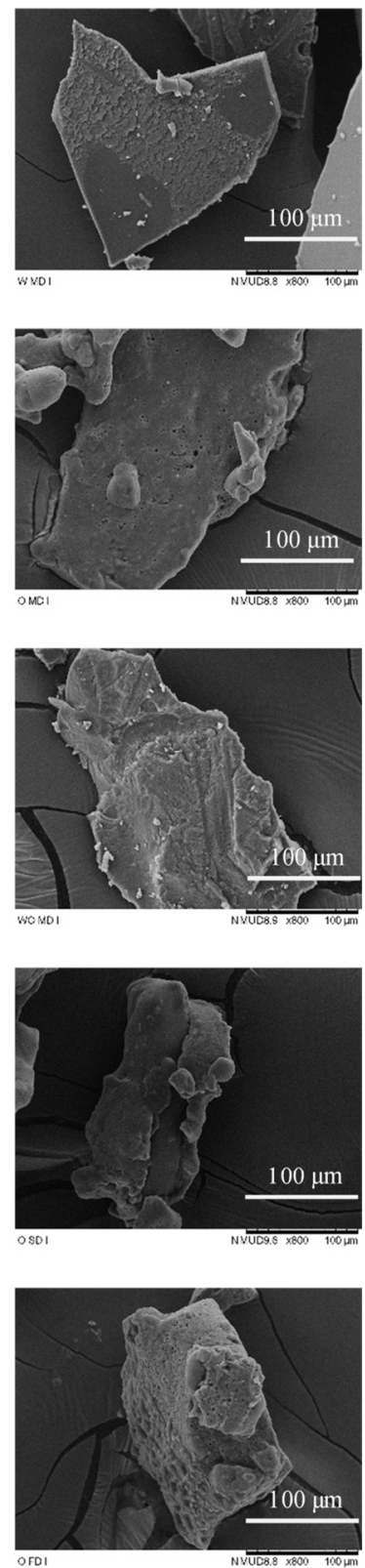

$2000 \times$
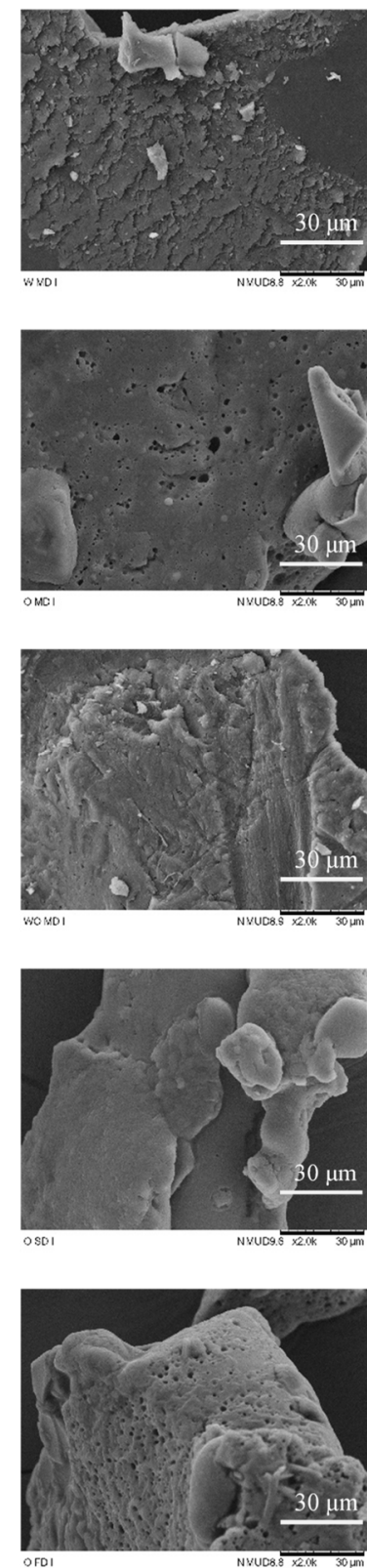

Figure 8. Microstructure of microcapsules after simulated intestinal digestion (magnification: 100 $\times, 800 \times, 2000 \times$ ). MFJSDW, MFJSD-O, and MFJSD-WO: microcapsules produced by microfluidic-jet spray drying, using WPI only, OSA only, and a combination of WPI/OSA $(50 / 50 w / w)$ as wall materials, respectively; SD-O: microcapsules produced by two-fluid nozzle spray drying, using OSA only as wall material; FD-O: microcapsules produced by freeze-drying, using OSA only as wall material; WPI: whey protein isolate; OSA: octenylsuccinic anhydride modified starch.

In order to have a clearer view on the digestion behaviour of the microcapsules at different stages, samples were stained to show the undigested oil droplets. As shown in Figure 9, all samples showed a similar behaviour from the initial stage to the gastric stage and intestinal stage. More specifically, all samples had very few oil droplets to be stained by Nile blue (shown as red colour) at the initial stage indicating the oil droplets were well encapsulated by the emulsifying materials at this stage. The dye cannot touch the oil droplets because the macromolecules of the wall materials, WPI and OSA, adhered to the surface of the oil droplets due to their lipophilicity. 
In the simulated stomach stage, under the effect of $\alpha$-amylase and pepsin, the WPI and OSA in the emulsion were gradually decomposed, and simultaneously the enclosed oil droplets were gradually released to react with the dye to develop colour. Therefore, in the simulated stomach stage, we can observe a large number of oil droplets were stained and many of them aggregated (Figure 9). In the simulated intestine stage, the oil droplets released from the simulated stomach stage were gradually broken down by the pancreatic lipase. The decomposed fatty acids and bile salts were combined to form micelles, which were used for subsequent absorption by intestinal wall cells.

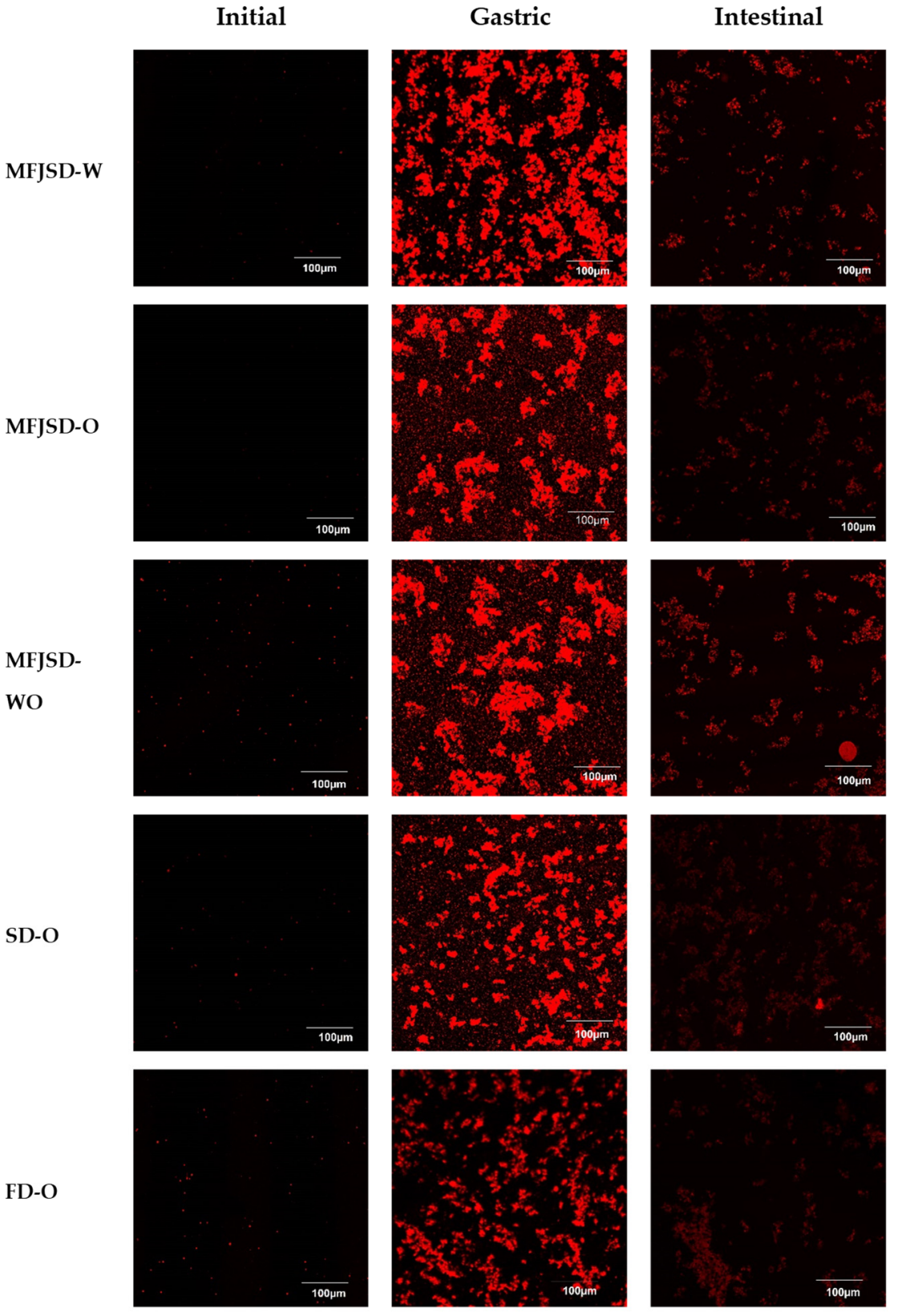

Figure 9. CLSM images showing the digestion behaviours of oil droplets in microcapsules after in vitro gastric and intestinal digestion. MFJSD-W, MFJSD-O, and MFJSD-WO: microcapsules produced by microfluidic-jet spray drying, using WPI only, OSA only, and a combination of WPI/OSA $(50 / 50 w / w)$ as wall materials, respectively; SD-O: microcapsules produced by two-fluid nozzle spray drying, using OSA only as wall material; FD-O: microcapsules produced by freeze-drying, using OSA only as wall material; WPI: whey protein isolate; OSA: octenylsuccinic anhydride modified starch. 


\section{Conclusions}

In this study, three microencapsulation techniques, namely microfluidic-jet spray drying (MFJSD), two-fluid nozzle spray drying (SD), and freeze-drying (FD), were employed to produce microcapsules for a comparison on the morphology, physiochemical properties, storage stabilities, and digestion behaviours of the powders. Three different types of wall materials, WPI only, OSA only, and WPI/OSA $50 \% / 50 \%$, were also applied to each drying method. As a result, the MFJSD microcapsules showed the higher microencapsulation efficiency, higher flowability, and better reconstitution properties than SD and FD microcapsules, mainly due to the good uniformity in the morphology and particle size. After 4-week storage at $55{ }^{\circ} \mathrm{C}, \mathrm{MFJSD}$ and FD microcapsules had higher retentions on carotenoids and $\omega-3$ PUFAs than SD microcapsules because of the smaller particle size of the spray-dried microcapsules. Moreover, through in vitro digestion trials, it was found that the differences in digestion behaviours of microcapsules were mainly dependent on their wall materials rather than microencapsulation techniques. This study has systematically investigated the co-encapsulation of carotenoids and fish oil by the MFJSD with comparison to the other two commonly used microencapsulation techniques. The results showed the feasibility of the application of the MFJSD for the encapsulation of lipophilic bioactives. It also provided important information on how different atomization mechanisms and drying techniques affect the properties of the final microcapsules.

Author Contributions: Conceptualization, Y.Z. and S.Y.Q.; methodology, Y.Z.; software, Y.Z.; validation, Y.Z., Y.P., and S.Y.Q.; formal analysis, Y.Z. and S.Y.Q.; investigation, Y.Z. and S.Y.Q.; resources, S.Y.Q.; data curation, Y.Z.; writing — original draft preparation, Y.Z.; writing—review and editing, Y.P., J.W., and S.Y.Q.; supervision, J.W. and S.Y.Q.; project administration, S.Y.Q.; funding acquisition, S.Y.Q. All authors have read and agreed to the published version of the manuscript.

Funding: This research was funded by Riddet Institute (Palmerston North, New Zealand), grant number is 9146-3711457.

Institutional Review Board Statement: Not applicable.

Informed Consent Statement: Not applicable.

Data Availability Statement: The data presented in this study are available upon request from the first author.

Conflicts of Interest: The authors declare no conflict of interest.

\section{References}

1. Hashemi, N.; Moghaddasi, H.; Rabiei, R.; Asadi, F.; Farahi, A. Eye health information systems in selected countries. J. Ophthalmic Vis. Res. 2018, 13, 333. [PubMed]

2. World Health Organization. World Report on Vision 2019; World Health Organization: Geneva, Switzerland, 2019.

3. Spiegler, E.; Kim, Y.-K.; Hoyos, B.; Narayanasamy, S.; Jiang, H.; Savio, N.; Curley, R.W.; Harrison, E.H.; Hammerling, U.; Quadro, L. $\beta$-apo-10'-carotenoids support normal embryonic development during vitamin A deficiency. Sci. Rep. 2018, 8, 8834. [CrossRef]

4. Islam, S.N.; Nusrat, T.; Begum, P.; Ahsan, M. Carotenoids and $\beta$-carotene in orange fleshed sweet potato: A possible solution to vitamin A deficiency. Food Chem. 2016, 199, 628-631. [CrossRef] [PubMed]

5. Kim, E.; Kim, H.; Kwon, O.; Chang, N. Associations between fruits, vegetables, vitamin A, $\beta$-carotene and flavonol dietary intake, and age-related macular degeneration in elderly women in Korea: The Fifth Korea National Health and Nutrition Examination Survey. Eur. J. Clin. Nutr. 2018, 72, 161. [CrossRef]

6. Buscemi, S.; Corleo, D.; Di Pace, F.; Petroni, M.L.; Satriano, A.; Marchesini, G. The effect of lutein on eye and extra-eye health. Nutrients 2018, 10, 1321. [CrossRef] [PubMed]

7. Moreillon, J.; Bowden, R.; Shelmadine, B. Fish oil and C-reactive protein. Bioact. Food Diet. Interv. Arthritis Relat. Inflamm. Dis. Bioact. Food Chronic Dis. States 2012, 393.

8. Wang, H.; Daggy, B.P. The role of fish oil in inflammatory eye diseases. Biomed. Hub. 2017, 2, 1-12. [CrossRef] [PubMed]

9. Kawakita, T.; Kawabata, F.; Tsuji, T.; Kawashima, M.; Shimmura, S.; Tsubota, K. Effects of dietary supplementation with fish oil on dry eye syndrome subjects: Randomized controlled trial. Biomed. Res. 2013, 34, 215-220. [CrossRef]

10. Cakiner-Egilmez, T. Omega 3 fatty acids and the eye. Insight 2008, 33, 20-27. [PubMed]

11. Tan, C.; Xue, J.; Lou, X.; Abbas, S.; Guan, Y.; Feng, B.; Zhang, X.; Xia, S. Liposomes as delivery systems for carotenoids: Comparative studies of loading ability, storage stability and in vitro release. Food Funct. 2014, 5, 1232-1240. [CrossRef] [PubMed] 
12. Voda, A.; Homan, N.; Witek, M.; Duijster, A.; van Dalen, G.; van der Sman, R.; Nijsse, J.; van Vliet, L.; Van As, H.; van Duynhoven, J. The impact of freeze-drying on microstructure and rehydration properties of carrot. Food Res. Int. 2012, 49, 687-693. [CrossRef]

13. Nail, S.L.; Gatlin, L.A. Freeze-drying: Principles and practice. In Pharmaceutical Dosage Forms-Parenteral Medications; CRC Press: Boca Raton, FL, USA, 2016; pp. 367-396.

14. Wu, W.D.; Amelia, R.; Hao, N.; Selomulya, C.; Zhao, D.; Chiu, Y.L.; Chen, X.D. Assembly of uniform photoluminescent microcomposites using a novel micro-fluidic-jet-spray-dryer. AlChE J. 2011, 57, 2726-2737. [CrossRef]

15. Liu, W.; Chen, X.; Selomulya, C. On the spray drying of uniform functional microparticles. Particuology 2015, 22, 1-12. [CrossRef]

16. Rogers, S.; Fang, Y.; Lin, S.X.Q.; Selomulya, C.; Chen, X.D. A monodisperse spray dryer for milk powder: Modelling the formation of insoluble material. Chem. Eng. Sci. 2012, 71, 75-84. [CrossRef]

17. Huang, E.; Quek, S.Y.; Fu, N.; Wu, W.D.; Chen, X.D. Co-encapsulation of coenzyme Q10 and vitamin E: A study of microcapsule formation and its relation to structure and functionalities using single droplet drying and micro-fluidic-jet spray drying. J. Food Eng. 2019, 247, 45-55. [CrossRef]

18. Wang, Y.; Liu, W.; Chen, X.D.; Selomulya, C. Micro-encapsulation and stabilization of DHA containing fish oil in protein-based emulsion through mono-disperse droplet spray dryer. J. Food Eng. 2016, 175, 74-84. [CrossRef]

19. Rizi, K.; Green, R.J.; Donaldson, M.; Williams, A.C. Production of pH-responsive microparticles by spray drying: Investigation of experimental parameter effects on morphological and release properties. J. Pharm. Sci. 2011, 100, 566-579. [CrossRef]

20. Carneiro, H.C.; Tonon, R.V.; Grosso, C.R.; Hubinger, M.D. Encapsulation efficiency and oxidative stability of flaxseed oil microencapsulated by spray drying using different combinations of wall materials. J. Food Eng. 2013, 115, 443-451. [CrossRef]

21. Wei, F.; Zhao, Q.; Lv, X.; Dong, X.-Y.; Feng, Y.-Q.; Chen, H. Rapid magnetic solid-phase extraction based on monodisperse magnetic single-crystal ferrite nanoparticles for the determination of free fatty acid content in edible oils. J. Agric. Food. Chem. 2012, 61, 76-83. [CrossRef]

22. Liu, H.; Zhang, Y.; Li, Q.; Zou, Y.; Shao, J.; Lan, S. Quantification of lutein and zeaxanthin in marigold (tagetes erecta 1.) and poultry feed by ultra-performance liquid chromatography and high performance liquid chromatography. J. Liq. Chromatogr. Relat. Technol. 2011, 34, 2653-2663. [CrossRef]

23. Raju, M.; Varakumar, S.; Lakshminarayana, R.; Krishnakantha, T.P.; Baskaran, V. Carotenoid composition and vitamin A activity of medicinally important green leafy vegetables. Food Chem. 2007, 101, 1598-1605. [CrossRef]

24. Minekus, M.; Alminger, M.; Alvito, P.; Ballance, S.; Bohn, T.; Bourlieu, C.; Carriere, F.; Boutrou, R.; Corredig, M.; Dupont, D. A standardised static in vitro digestion method suitable for food-An international consensus. Food Funct. 2014, 5, 1113-1124. [CrossRef] [PubMed]

25. Lueamsaisuk, C.; Lentle, R.; MacGibbon, A.; Matia-Merino, L.; Golding, M. The effect of lactoferrin on physical changes in phospholipid stabilised emulsions during neonatal in vitro gastric digestion: Does synergism of pepsin and lipase promote lipolysis in protein-stabilised emulsions? Food Hydrocoll. 2015, 43, 785-793. [CrossRef]

26. Wu, W.D.; Patel, K.C.; Rogers, S.; Chen, X.D. Monodisperse droplet generators as potential atomizers for spray drying technology. Dry. Technol. 2007, 25, 1907-1916. [CrossRef]

27. Al-Khattawi, A.; Bayly, A.; Phillips, A.; Wilson, D. The design and scale-up of spray dried particle delivery systems. Expert Opin. Drug Deliv. 2018, 15, 47-63. [CrossRef] [PubMed]

28. Frascareli, E.C.; Silva, V.M.; Tonon, R.V.; Hubinger, M.D. Determination of critical storage conditions of coffee oil microcapsules by coupling water sorption isotherms and glass transition temperature. Int. J. Food Sci. Technol. 2012, 47, 1044-1054. [CrossRef]

29. Wang, Y.; Che, L.; Fu, N.; Chen, X.D.; Selomulya, C. Surface formation phenomena of DHA-containing emulsion during convective droplet drying. J. Food Eng. 2015, 150, 50-61. [CrossRef]

30. Hategekimana, J.; Masamba, K.G.; Ma, J.; Zhong, F. Encapsulation of vitamin E: Effect of physicochemical properties of wall material on retention and stability. Carbohydr. Polym. 2015, 124, 172-179. [CrossRef]

31. Yan, C.; McClements, D.J.; Zou, L.; Liu, W. A stable high internal phase emulsion fabricated with OSA-modified starch: An improvement in $\beta$-carotene stability and bioaccessibility. Food Funct. 2019, 10, 5446-5460. [CrossRef]

32. Santos, D.; Maurício, A.C.; Sencadas, V.; Santos, J.D.; Fernandes, M.H.; Gomes, P.S. Spray Drying: An Overview. In BiomaterialsPhysics and Chemistry-New Edition; IntechOpen: London, UK, 2018; pp. 9-15.

33. Goyal, A.; Sharma, V.; Sihag, M.K.; Tomar, S.; Arora, S.; Sabikhi, L.; Singh, A. Development and physico-chemical characterization of microencapsulated flaxseed oil powder: A functional ingredient for omega-3 fortification. Powder Technol. 2015, 286, 527-537. [CrossRef]

34. Elversson, J.; Millqvist-Fureby, A. Particle size and density in spray drying-Effects of carbohydrate properties. J. Pharm. Sci. 2005, 94, 2049-2060. [CrossRef] [PubMed]

35. Fernandes, R.V.d.B.; Borges, S.V.; Botrel, D.A. Influence of spray drying operating conditions on microencapsulated rosemary essential oil properties. Food Sci. Technol. 2013, 33, 171-178. [CrossRef]

36. Desobry, S.A.; Netto, F.M.; Labuza, T.P. Comparison of spray-drying, drum-drying and freeze-drying for $\beta$-carotene encapsulation and preservation. J. Food Sci. 1997, 62, 1158-1162. [CrossRef]

37. Arpagaus, C. PLA/PLGA nanoparticles prepared by nano spray drying. J. Pharm. Investig. 2019, 49, 405-426. [CrossRef]

38. Pénicaud, C.; Achir, N.; Dhuique-Mayer, C.; Dornier, M.; Bohuon, P. Degradation of $\beta$-carotene during fruit and vegetable processing or storage: Reaction mechanisms and kinetic aspects: A review. Fruits 2011, 66, 417-440. [CrossRef] 
39. Fratianni, A.; Niro, S.; Messia, M.C.; Cinquanta, L.; Panfili, G.; Albanese, D.; Di Matteo, M. Kinetics of carotenoids degradation and furosine formation in dried apricots (Prunus armeniaca L.). Food Res. Int. 2017, 99, 862-867. [CrossRef] [PubMed]

40. Fournier, V.; Destaillats, F.; Juanéda, P.; Dionisi, F.; Lambelet, P.; Sébédio, J.L.; Berdeaux, O. Thermal degradation of long-chain polyunsaturated fatty acids during deodorization of fish oil. Eur. J. Lipid Sci. Technol. 2006, 108, 33-42. [CrossRef]

41. Salvia-Trujillo, L.; Qian, C.; Martín-Belloso, O.; McClements, D. Influence of particle size on lipid digestion and $\beta$-carotene bioaccessibility in emulsions and nanoemulsions. Food Chem. 2013, 141, 1472-1480. [CrossRef] [PubMed]

42. Li, J.; Ye, A.; Lee, S.J.; Singh, H. Physicochemical behaviour of WPI-stabilized emulsions in in vitro gastric and intestinal conditions. Colloids Surf. B Biointerfaces 2013, 111, 80-87. [CrossRef]

43. Zhang, R.; Zhang, Z.; Zhang, H.; Decker, E.A.; McClements, D.J. Influence of lipid type on gastrointestinal fate of oil-in-water emulsions: In vitro digestion study. Food Res. Int. 2015, 75, 71-78. [CrossRef]

44. Singh, H.; Ye, A.; Horne, D. Structuring food emulsions in the gastrointestinal tract to modify lipid digestion. Prog. Lipid Res. 2009, 48, 92-100. [CrossRef]

45. López-Castejón, M.L.; Bengoechea, C.; Espinosa, S.; Carrera, C. Characterization of prebiotic emulsions stabilized by inulin and $\beta$-lactoglobulin. Food Hydrocoll. 2019, 87, 382-393. [CrossRef]

46. Silva, H.D.; Cerqueira, M.Â.; Vicente, A.A. Nanoemulsions for food applications: Development and characterization. Food Bioprocess Technol. 2012, 5, 854-867. [CrossRef]

47. Bello-Pérez, L.A.; Bello-Flores, C.A.; del Carmen Nunez-Santiago, M.; Coronel-Aguilera, C.P.; Alvarez-Ramirez, J. Effect of the degree of substitution of octenyl succinic anhydride-banana starch on emulsion stability. Carbohydr. Polym. 2015, 132, 17-24. [CrossRef] [PubMed] 